\title{
Arctigenin inhibits the activation of the mTOR pathway, resulting in autophagic cell death and decreased ER expression in ER-positive human breast cancer cells
}

\author{
THRESSI MAXWELL, KYU SHIK LEE, SOYOUNG KIM and KYUNG-SOO NAM \\ Department of Pharmacology, School of Medicine and Intractable Disease Research Center, \\ Dongguk University, Gyeongju 38066, Republic of Korea
}

Received November 7, 2017; Accepted February 6, 2018

DOI: $10.3892 /$ ijo.2018.4271

\begin{abstract}
Arctigenin, a member of the Asteraceae family, is a biologically active lignan that is consumed worldwide due to its several health benefits. However, its use may pose a problem for patients with estrogen receptor (ER) $\alpha$-positive breast cancer, since studies have shown that arctigenin is a phytoestrogen that exerts a proliferative effect by binding to the ER. Thus, in this study, we examined the effect of arctigenin on ER $\alpha$-positive MCF-7 human breast cancer cells to determine whether the consumption of arctigenin is safe for patients with breast cancer. First, we found that arctigenin inhibited the viability of the MCF-7 cells, and colony formation assay confirmed that this effect was cytotoxic rather than cytostatic. The cytotoxic effects were not mediated by cell cycle arrest, apoptosis, or necroptosis, despite DNA damage, as indicated by poly(ADPribose) polymerase (PARP) cleavage and phosphorylated H2A.X. An increase in lipidated LC3, a marker of autophagosome formation, was observed, indicating that autophagy was induced by arctigenin, which was found to be triggered by
\end{abstract}

Correspondence to: Professor Kyung-Soo Nam or Professor Soyoung Kim, Department of Pharmacology, School of Medicine and Intractable Disease Research Center, Dongguk University, 123 Dongdae-ro, Gyeongju 38066, Republic of Korea

E-mail: namks@dongguk.ac.kr

E-mail: soyoungkim@dongguk.ac.kr

Abbreviations: ER, estrogen receptor; PR, progesterone receptor; Bcl-xL, B-cell lymphoma-extra large; AIF, apoptosis-inducing factor; PARP, poly(ADP-ribose) polymerase; ADP, adenosine diphosphate; ATR, ATM-Rad3-related; ATM, ataxia telangiectasia mutated; GAPDH, glyceraldehyde-3-phosphate dehydrogenase; AMPK, adenosine monophosphate-activated protein kinase; mTOR, mechanistic target of rapamycin; S6K1, ribosomal protein S6 kinase beta-1; S6, ribosomal protein S6; 4EBP1, eukaryotic translation initiation factor 4E-binding protein $1 ; L C 3$, microtubule-associated protein 1A/1B-light chain 3; PCR, polymerase chain reaction

Key words: arctigenin, phytoestrogen, breast cancer, estrogen receptor, autophagy, DNA damage, tamoxifen, MCF-7 cells the inhibition of the mechanistic target of rapamycin (mTOR) pathway. We then examined the effects of arctigenin on ER $\alpha$ expression and determined whether it affects the sensitivity of the cells to tamoxifen, as tamoxifen is commonly used against hormone-responsive cancers and is known to act via the ER $\alpha$. We found that treatment with arctigenin effectively downregulated ER $\alpha$ expression, which was found to be a consequence of the inhibition of the mTOR pathway. However, treatment with arctigenin in combination with tamoxifen did not affect the sensitivity of the cells to tamoxifen, but instead, exerted a synergistic effect. On the whole, our data indicate that the phytoestrogen, arctigenin, mainly targeted the mTOR pathway in ER $\alpha$-positive MCF-7 human breast cancer cells, leading to autophagy-induced cell death and the downregulation of ER $\alpha$ expression. Furthermore, the synergistic effects between arctigenin and tamoxifen suggest that the consumption of arctigenin is not only safe for patients with hormone-sensitive cancers, but may also be an effective co-treatment.

\section{Introduction}

Arctigenin is a bioactive lignan and a member of the Asteraceae family isolated from the seeds of Arctium lappa. The roots of Arctium lappa, commonly known as greater burdock, are consumed as a vegetable worldwide. Dried burdock roots have been used in folk medicine as a diuretic, diaphoretic and blood purifying agent (1). Moreover, arctigenin has also been shown to have anti-viral (2-4), anti-inflammatory (5) and immunomodulatory activities (6). It is one of the major ingredients in Essiac tea, which is used as an alternative treatment for certain types of cancer (7). The anticancer effects of arctigenin have also been reported in various human cancer cell lines (8-16), in which arctigenin induced apoptosis mainly via the mitochondrial pathway $(8,10,12,15,16)$ and cell cycle arrest. Reports of G0/G1 arrest in lung $(13,14)$ and bladder $(16)$ cancer cells, but $\mathrm{G} 2 / \mathrm{M}$ arrest in colon cancer cells (17), suggest that arctigenin exerts differential effects at the molecular level in different cell types.

However, studies on the effects of arctigenin in breast cancer cells are limited. Hsieh et al demonstrated that arctigenin markedly inhibited the growth of estrogen receptor (ER) $\alpha$-negative MDA-MB-231 cells by triggering the 
mitochondrial apoptotic pathway (8). Another recent study demonstrated that signal transducer and activator of transcription 3 (STAT3) was inhibited by arctigenin, leading to apoptosis and tumor suppression of the same breast cancer cell line (18). We have also previously reported that arctigenin exerts anti-metastatic effects in breast cancer cells, regardless of ER $\alpha$ expression (19). The effects of arctigenin on ER $\beta$ in Th17 cells as an agonist have also been reported (20). However, to the best of our knowledge, its effects on hormone-responsive breast cancer cells have not yet been fully elucidated. Although both ER receptors display extensive similarities, in that they bind to estradiol and related compounds and initiate the transcription of DNA sequences referred to as estrogen response elements (ERE), they are encoded by distinct genes located on different chromosomes and have significantly different primary sequences in their ligand binding domains (21). Thus, ER subtypes can bind certain ligands with different affinities, and these ligands may also have different agonist or antagonist characters downstream. Due to the diversity of estrogen target tissues, and given that the levels and proportion of ER $\alpha$ and ER $\beta$ differ in different target cells, there is some overlap between ER $\alpha$ and ER $\beta$, but also some differences with respect to ligand interaction or activity that may be important in the biological actions at the tissue level. In breast cancer, ER $\beta$ is considered to play a protective role. ER $\beta$ is lost in the majority of breast tumors (22) as a result of ER $\beta$ promoter methylation and is a possible tumor suppressor gene. On the other hand, $\mathrm{ER} \alpha$ expression is measured in order to come to a clinical decision on the treatment of course for patients with breast cancer. Since it has been reported that arctigenin is a phytoestrogen (23), there may be a possibility that it could bind to ER $\alpha$ and exert an inhibitory or proliferative effect in ER $\alpha$-positive breast cancer cells. Therefore, it is important to understand the effects of arctigenin on ER $\alpha$-positive cells.

Thus, in this study, to determine whether arctigenin is safe for consumption by patients with ER $\alpha$-positive breast cancer, we investigated the effects of arctigenin on ER $\alpha$-positive MCF-7 human breast cancer cells. We examined its effects on cell viability and explored the underlying mechanisms. We also examined the effects of arctigenin on ER $\alpha$ expression in order to verify whether it affects the cytotoxicity of tamoxifen.

\section{Materials and methods}

Cell culture. MCF-7 and MDA-MB-231 human breast cancer cells were purchased from the Korean Cell Line Bank (Seoul, Korea). MCF-7 cells were cultured in Dulbecco's modified Eagle's medium (DMEM; Welgene Daegu, Korea) supplemented with $10 \%$ fetal bovine serum-FBS (ATCC, Rockville, MD, USA), $10 \mu \mathrm{g} / \mathrm{ml}$ insulin (Welgene) and $1 \%$ antibioticantimycotic solution (Welgene). Phenol red-free DMEM (Welgene) containing 10\% dextran-coated charcoal-stripped FBS and $10 \mathrm{nM}$ estradiol (Sigma, St. Louis, MO, USA) was used only for the experiments with tamoxifen (AG Scientific Inc., San Diego, CA, USA). For use as positive controls of RIPK3, MDA-MB-231 cells were cultured in DMEM supplemented with $10 \%$ FBS and antibiotic-antimycotic solution.

SRB cell cytotoxicity assay. A total of 5,000 cells/well seeded in 96-well plates were treated with conditioned medium containing $0,1,2.5,5,10,25,50,100$ and $200 \mu \mathrm{M}$ arctigenin (Santa Cruz Biotechnology, Inc., Santa Cruz, CA, USA) and $2 \%$ FBS for 24, 48 or $72 \mathrm{~h}$. The medium was removed, and the cells were fixed with $100 \mu \mathrm{l}$ ice-cold $20 \%$ trichloroacetic acid (Samchun Pure Chemical, Pyongtaek, Korea) for $1 \mathrm{~h}$ at $4^{\circ} \mathrm{C}$. The plates were then washed 5 times under slow-running tap water and allowed to air-dry overnight. A solution of $50 \mu 1$ $0.4 \%$ sulforhodamine B (SRB; Sigma) was added for staining at room temperature for $30 \mathrm{~min}$. Unbound SRB was washed off with $1 \%$ acetic acid, and the plate was air-dried. Bound SRB was solubilized by the addition of $100 \mu \mathrm{l}$ of $10 \mathrm{mM}$ Tris pH 10.5 to each well and shaken for $5 \mathrm{~min}$ before reading the absorbance at $510 \mathrm{~nm}$ using a Multi-Detection Microplate Reader (Molecular Devices, Sunnyvale, CA, USA).

Colony formation assay. A total of 700 cells/well seeded in 6-well plates were treated with conditioned medium containing $0,2.5,50$ and $200 \mu \mathrm{M}$ arctigenin in $2 \% \mathrm{FBS}$, and were allowed to grow for a week until the colonies of appropriate size were formed. The medium was removed, and the cells were fixed with $1 \mathrm{ml} \mathrm{10 \%} \mathrm{formaldehyde} \mathrm{for} 20 \mathrm{~min}$ at room temperature and washed with PBS. The colonies were stained with $1 \mathrm{ml}$ $0.01 \%$ crystal violet (Sigma) for $40 \mathrm{~min}$ at room temperature and washed with PBS and air-dried. Light microscopic images were captured and colonies were counted using ImageJ software (National Institute of Mental Health, Bethesda, MD, USA), as per the manufacturer's instructions.

Cell cycle analysis by flow cytometry. For cell cycle analysis, the cells grown in medium containing 0, 2.5, 50 and $200 \mu \mathrm{M}$ arctigenin and $2 \%$ FBS for $72 \mathrm{~h}$ were trypsinized after washing with PBS, centrifuged at $100 \mathrm{x}$ g for $3 \mathrm{~min}$, and fixed in cold $70 \%$ ethanol. Following centrifugation, the cells were washed with PBS containing $2 \%$ FBS and stained in the dark with $20 \mu \mathrm{g} / \mathrm{ml}$ propidium iodide (Sigma) and $40 \mu \mathrm{g} / \mathrm{ml}$ RNase A (Sigma) for $30 \mathrm{~min}$ at room temperature. The cells were then analyzed using a FACS Calibur II flow cytometer (BD Biosciences, San Jose, CA, USA).

Protein extraction and western blot analysis. The cells were treated with conditioned medium containing $0,1,2.5,5,10$, $25,50,100$ and $200 \mu \mathrm{M}$ arctigenin for $72 \mathrm{~h}$. For treatment with inhibitors, the cells were treated with $500 \mathrm{nM}$ MG132 (Cayman Chemical, Ann Arbor, MI, USA), $10 \mu \mathrm{M}$ chloroquine (Sigma), $20 \mathrm{mM} \mathrm{NH}_{4} \mathrm{Cl}$ (Stemcell Technologies, Vancouver, Canada), $2.5 \mu \mathrm{M}$ decitabine (AZA; LC Laboratories, Woburn, MA, USA), or $5 \mathrm{nM}$ trichostatin A (TSA; ApexBio, Houston, TX, USA) $30 \mathrm{~min}$ prior to arctigenin treatment. The cells were lysed with RIPA buffer $(50 \mathrm{mM}$ Tris- $\mathrm{HCl} \mathrm{pH} 7.5$ with $150 \mathrm{mM}$ $\mathrm{NaCl}, 1 \%$ Triton X-100, $1 \%$ sodium deoxycholate, $0.1 \%$ sodium dodecyl sulphate-SDS and $2 \mathrm{mM}$ EDTA) containing phosphatase and protease inhibitor cocktail (GenDEPOT, Barker, TX, USA). In the lysates, the debris was cleared off by centrifugation at $17,000 \mathrm{x} \mathrm{g}$ for $20 \mathrm{~min}$ at $4^{\circ} \mathrm{C}$ and protein concentrations were determined using bicinchoninic acid reagent (Sigma). The proteins were separated by SDS-PAGE, and transferred onto polyvinylidene fluoride (PVDF) membranes at $100 \mathrm{~V}$ for $40 \mathrm{~min}$. The membranes were blocked in 5\% skim milk in Tris-buffered saline-Tween-20 buffer $(10 \mathrm{mM}$ Tris- $\mathrm{HCl}$, $150 \mathrm{mM} \mathrm{NaCl}, 0.1 \%$ Tween-20) for $1 \mathrm{~h}$ at room temperature. 
The following primary monoclonal antibodies from Cell Signaling Technology (Beverly, MA, USA): B-cell lymphomaextra-large (Bcl-xL, \#2764), apoptosis-inducing factor (AIF, \#5318), poly(ADP-ribose) polymerase (PARP, \#9542), caspase-7 (\#9492), microtubule-associated protein 1A/1B-light chain 3 (LC3A/B, \#4108), estrogen receptor $\alpha$ (ER $\alpha, \# 8644)$ phosphorylated forms of histone 2A.X (p-H2A.X, \#9718), ataxia telangiectasia mutated-Rad3-related (p-ATR, \#2853), phosphorylated and total forms of mechanistic target of rapamycin (p-mTOR, \#2971; and mTOR, \#2972), ribosomal protein S6 kinase beta-1 (p-S6K1, \#9205; and S6K, \#9202), ribosomal protein S6 (p-S6, \#4858; and S6, \#2217), adenosine monophosphate-activated protein kinase (p-AMPK, \#2535; and AMPK, \#2532), or from Santa Cruz Biotechnology: RIPK3 (sc-374639), RAD51 (sc-8349), $\beta$-actin (sc-69879) were diluted 3,000-fold and incubated with the blots overnight at $4^{\circ} \mathrm{C}$. Corresponding HRP-conjugated secondary antibody from Santa Cruz Biotechnology goat anti-rabbit (sc-2004) or goat anti-mouse (sc-2005) was diluted 5,000-fold, and incubated with the blots for $2 \mathrm{~h}$ at room temperature. The blots were developed and imaged using Luminescent Image Analyzer LAS-4000 (Fujifilm, Tokyo, Japan). Densitometric analysis was performed using Scion Image (Scion Corporation, Frederick, MD, USA) with data from at least 3 independent experiments.

RNA extraction and cDNA synthesis. RNA was isolated from the cells treated with conditioned medium containing arctigenin or rapamycin (LC Laboratories) using the easy-BLUE ${ }^{\mathrm{TM}}$ Total RNA Extraction kit (iNtRON Biotechnology, Inc., Sungnam, Korea), which was performed in accordance with the manufacturer's instructions. The RNA concentrations were determined using a NanoDrop spectrophotometer (Schimadzu Scientific Instruments, Columbia, MD, USA). A total of $1 \mu \mathrm{g}$ of total RNA was reverse transcribed using a Primescript Reverse Transcriptase (Takara, Shiga, Japan).

Real-time PCR. Real-time PCR reactions were performed in triplicate in $10 \mu \mathrm{l}$ total volumes with $1 \mu \mathrm{l}$ of each primer (0.5 $\mu \mathrm{M}$ final concentrations) and $5 \mu \mathrm{l}$ of SYBR-Green qPCR $2 \mathrm{X}$ master mix (Cell Safe, Suwon, Korea) in the $\mathrm{Eco}^{\mathrm{TM}}$ Real-Time PCR system (Illumina Inc., San Diego, CA, USA). The PCR products were verified by a melt curve analysis and relative intensity compared with the controls. The primer sequences and annealing temperatures for the target genes were as follows: progesterone receptor (PR) forward, 5'-AAC TTG CAT GAT CTT GTC AAA CA-3' and reverse, 5'-CAC CAT CCC TGC CAA TAT CT-3', 57 ${ }^{\circ} \mathrm{C}$; ER $\alpha$ forward, 5'-CAC ATG AGT AAC AAA GGC ATG G-3' and reverse, 5'-ATG AAG TAG AGC CCG CAG TG-3, $58^{\circ} \mathrm{C}$ and GAPDH (amplified as an internal control) forward, 5'-ATC CCA TCA CCA TCT TCC AG-3' and reverse, 5'-TTC TAG ACG GCA GGT CAG GT-3'.

Determination of combined drug interactions. To determine the synergistic, additive, or antagonistic effects of arctigenin in combination with tamoxifen, various concentrations of tamoxifen $(0,5$ and $10 \mu \mathrm{M})$ were combined with various concentrations of arctigenin for the determination of their effects on MCF-7 cell proliferation. The association between the dose and effect for single agents and their combinations were analyzed, as previously described by Chou and Talalay (24) using the Compusyn Version 1.0 free software package (Compusyn Inc., USA). The combination index (CI) values were calculated for each dose and the corresponding effect level, presented as the fraction affected (Fa). The Fa-CI graph was plotted for a graphical representation of drug interactions. The CI values provide a quantitative definition for the additive effect $(\mathrm{CI}=1)$, the synergistic effect $(\mathrm{CI}<1)$ and the antagonistic effect $(\mathrm{CI}>1)$ of drug combinations.

Statistical analysis. Statistical significance was determined using one-way ANOVA and Tukey's post hoc test with SPSS V20.0 software (SPSS, Inc., Chicago, IL, USA). The results are presented as the means $\pm \mathrm{SD}$. P-values $<0.05$ were considered to indicate statistically significant differences.

\section{Results}

Arctigenin is cytotoxic, not cytostatic, to ER $\alpha$-positive MCF-7 human breast cancer cells. First, we assessed the effects of arctigenin on the viability of ER $\alpha$-positive human breast cancer cells. The MCF-7 cells were grown in medium containing various concentrations of arctigenin for 24,48 or $72 \mathrm{~h}$. SRB cell cytotoxicity assay revealed that the effects of arctigenin were concentration- and time-dependent. Treatment with arctigenin at a concentration as low as $1 \mu \mathrm{M}$ for $24 \mathrm{~h}$ significantly decreased the viability of the MCF-7 cells, and treatment with arctigenin at $200 \mu \mathrm{M}$ for $72 \mathrm{~h}$ inhibited cell viability by as much as $50 \%$ (Fig. 1A).

However, from the SRB assay, we were unable to determine whether arctigenin suppressed cell proliferation (cytostatic effect) or induced cell death (cytotoxic effect). Hence, we conducted a colony formation assay to confirm this. When the cells were treated with arctigenin for $72 \mathrm{~h}$ and then allowed to grow in arctigenin-free medium, the survival fraction of the cells treated with $50 \mu \mathrm{M}$ arctigenin was $20 \%$ that of control, and this was even lower in the cells treated with $200 \mu \mathrm{M}$ arctigenin (Fig. 1B and C). Arctigenin suppressed the ability of the cells to form colonies and confirmed the cytotoxic effects of arctigenin.

Arctigenin treatment does not induce the apoptosis or necroptosis of MCF-7 human breast cancer cells. Since arctigenin was found to be cytotoxic, we wished to determine whether the cytotoxic effects of arctigenin are mediated through the induction of cell cycle arrest, as arctigenin has previously been reported to affect the cell cycle $(10,14,16)$. Surprisingly, in contrast to the findings of other studies, the results of cell cycle analysis revealed that treatment with arctigenin for up to $72 \mathrm{~h}$ had no effect on the MCF-7 cells (Fig. 2A).

Arctigenin has previously been reported to induce the apoptosis of several cancer cell lines (8-12,14-16). Since the MCF-7 cells do not express caspase-3 (25), we examined the effector caspase, caspase-7, which is known to induce the apoptosis of MCF-7 cells. The caspase-7 levels remained unaltered with arctigenin treatment, and its activation in the form of cleaved caspase was not detected (Fig. 2B). The expression levels of Bcl-xL, the anti-apoptotic protein involved in preventing apoptosis via the mitochondrial pathway, and AIF 
A

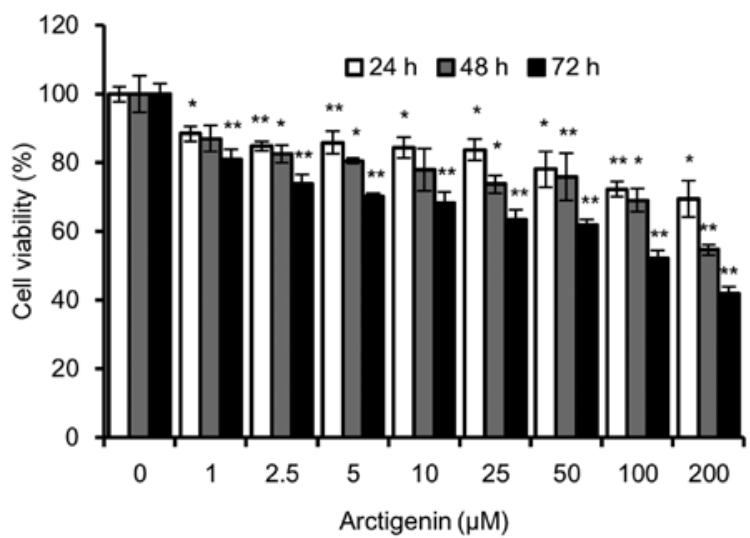

B

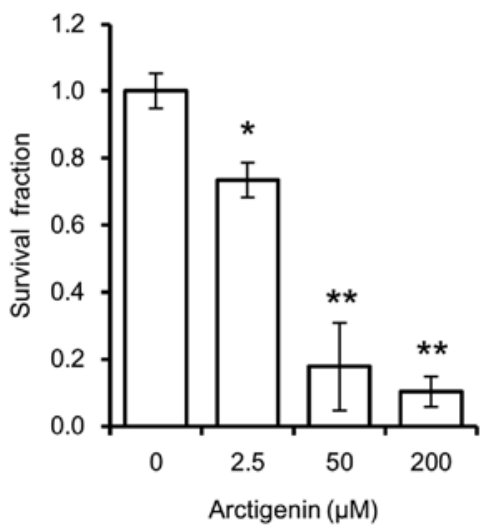

C

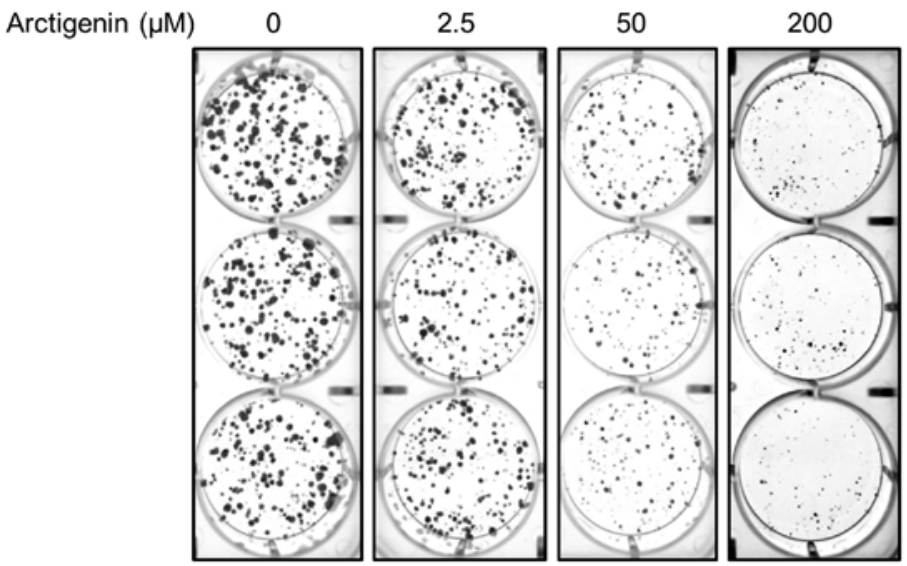

Figure 1. Arctigenin is cytotoxic to MCF-7 human breast cancer cells. (A) The viability of the MCF-7 cells treated with $0,1,2.5,5,10,25,50,100$ and $200 \mu \mathrm{M}$ arctigenin for 24,48 , or $72 \mathrm{~h}$ measured by SRB assay was decreased in a concentration- and time-dependent manner. (B) Quantification of colony formation assay, using ImageJ software, of cells treated with $0,2.5,50$ and $200 \mu \mathrm{M}$ arctigenin for $72 \mathrm{~h}$ and then allowed to grow in arctigenin-free medium for 2 weeks confirmed that arctigenin was not cytostatic but cytotoxic. (C) Representative images of colony formation assay. Graphs represent the means \pm SD of at least 3 independent experiments. $\mathrm{P}$-values were compared to the controls treated with $0 \mu \mathrm{M}$ arctigenin; ${ }^{*} \mathrm{P}<0.05$ and ${ }^{* *} \mathrm{P}<0.01$.

were also not altered by treatment with arctigenin (Fig. 2B). Hence, our data indicated that arctigenin did not induce the apoptosis of MCF-7 cells.

Necroptosis is a non-apoptotic form of cell death that resembles necrosis morphologically; nonetheless, it can be induced by the activation of death receptors. Several stimuli are known to induce necroptosis via protein kinase receptorinteracting serine/threonine-protein kinase 3 (RIPK3), which is now an accepted marker for necroptosis (26). Hence, in this study, we analyzed whether arctigenin induced the necroptosis of the MCF-7 cells. Untreated MDA-MB-231 human breast cancer cells were used as a positive control, since they have previously been shown to express RIPK3 (27). Our results from western blot analysis (Fig. 2C) revealed that treatment with arctigenin at a concentration as high as $200 \mu \mathrm{M}$ for up to $72 \mathrm{~h}$ did not induce RIPK3 expression. Therefore, it was concluded that the cytotoxic effects of arctigenin on the MCF-7 cells did not involve apoptosis or necroptosis.

Cytotoxic effects of arctigenin on MCF-7 human breast cancer cells are caused by mTOR inhibition, leading to autophagic cell death and DNA damage. Finally, we examined whether the arctigenin-induced cell cytotoxicity was due to autophagic cell death. Autophagy is a bulk recycling stress response in cells.
It predominantly activates the catabolic pathways that help cells survive under conditions in which the nutrient or energy supply is low, or in which there are other forms of stress. In the case of cancer cells, it can aid in cell survival, as well as in the development of drug resistance (28). However, it has also been reported that cells undergo autophagy-induced cell death, if the stress is beyond their comprehension. Previous studies have indicated that arctigenin induces autophagy, which can lead to the death of several cell lines (11,20,29-31). Therefore, in this study, to examine the autophagic activity of MCF-7 cells in response to arctigenin treatment, we analyzed the conversion of LC3 (LC3-I) into LC3-II. LC3 is a specific marker of autophagolysosome formation, which occurs throughout the process of autophagy (32), and a higher ratio of LC3-II/LC3-I means a higher autophagic activity. Using western blot analysis, we found that the untreated cells had no detectable levels of LC3-II and very low levels of LC3-I. The expression of both LC3 types along with the ratio of LC3-II/LC3-I increased, in a concentration-dependent manner with arctigenin treatment (Fig. 3A). This indicated that treatment with arctigenin at a concentration as low as $1 \mu \mathrm{M}$ induced autophagy in MCF-7 cells.

The results of western blot analyses also revealed that the phosphorylation of H2A.X and PARP cleavage was induced 
A
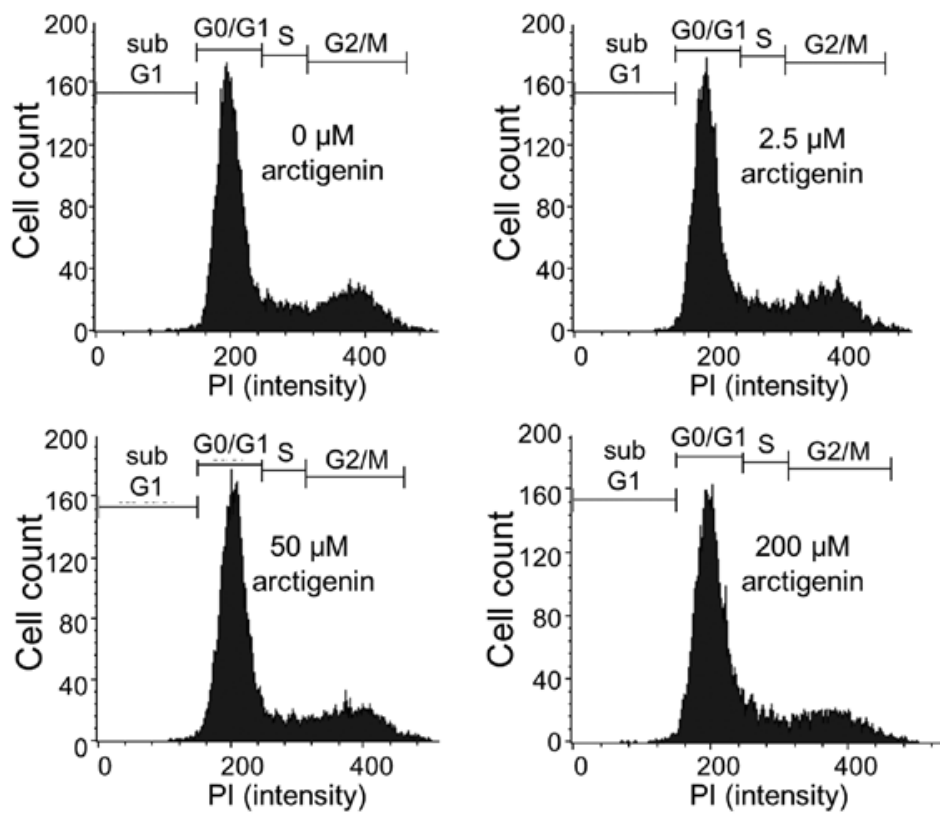

\begin{tabular}{|c|c|c|c|}
\hline Arctigenin & G0/G1 (\%) & $\underline{\mathrm{S}(\%)}$ & $\underline{\mathrm{G} / \mathrm{M}(\%)}$ \\
\hline $0 \mu \mathrm{M}$ & 68.10 & 9.74 & 21.80 \\
\hline $2.5 \mu \mathrm{M}$ & 67.88 & 9.89 & 22.03 \\
\hline $50 \mu \mathrm{M}$ & 70.43 & 8.88 & 20.03 \\
\hline $200 \mu \mathrm{M}$ & 70.79 & 10.46 & 18.02 \\
\hline
\end{tabular}

B

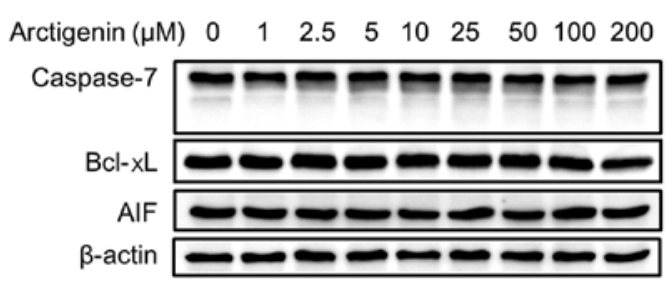

C

Arctigenin $(\mu \mathrm{M}) \quad 0 \quad 12.55102550100200+$ RIPK3 $\beta$-actin
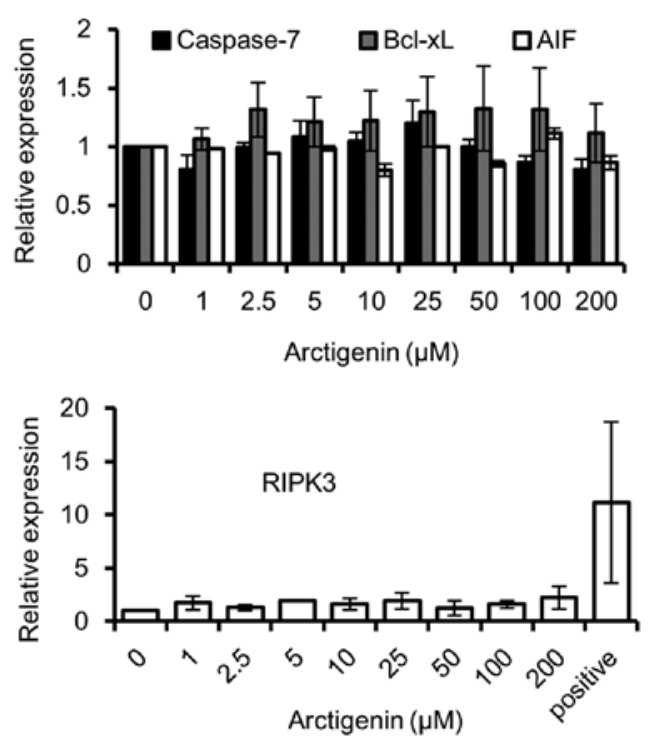

Figure 2. Arctigenin does not cause cell cycle arrest, apoptosis, or the necroptosis of MCF-7 human breast cancer cells. (A) Flow cytometric analysis and population distribution of MCF-7 cells treated with $0,2.5,50$ and $200 \mu \mathrm{M}$ arctigenin for $72 \mathrm{~h}$. The x-axis represents the fluorescence intensity of propidium iodide and the $\mathrm{y}$-axis represents the number of cells/channel. (B) Western blot analysis revealed that treatment of the MCF-7 cells with arctigenin for $72 \mathrm{~h}$ did not alter the levels of the apoptotic markers: The anti-apoptotic protein Bcl-xL, apoptosis- inducing factor (AIF) and the effector caspase, caspase-7. (C) Treatment with arctigenin for $72 \mathrm{~h}$ failed to induce the expression of the necroptosis marker, RIPK3, confirming that arctigenin does not cause the necroptosis of MCF-7 cells. (+) MDA-MB-231 human breast cancer cells, previously reported (27) to express detectable levels of RIPK3, were used as the positive control. Graphs represent the means \pm SD of at least 3 independent experiments. P-values were compared to the controls treated with $0 \mu \mathrm{M}$ arctigenin, and the results revealed no statistical significance.

in a concentration-dependent manner with arctigenin treatment (Fig. 3B). H2A.X is a histone H2A family protein, which is phosphorylated and recruited to sites of double-strand
DNA breaks and hence is considered a marker for DNA damage (33). PARP is a DNA repair enzyme cleaved by activated caspases. Its fragmentation is a marker of apoptosis. 
A

Arctigenin $(\mu \mathrm{M}) 0 \quad 1 \quad 2.5 \quad 5 \quad 10 \quad 25 \quad 50 \quad 100 \quad 200$
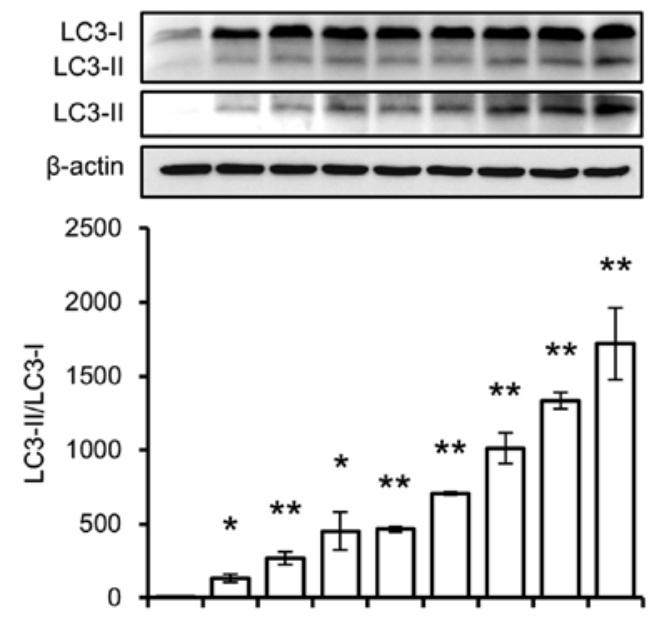

C

Arctigenin $(\mu \mathrm{M}) 0 \quad 1 \quad 2.5 \quad 5 \quad 10 \quad 25 \quad 50 \quad 100 \quad 200$
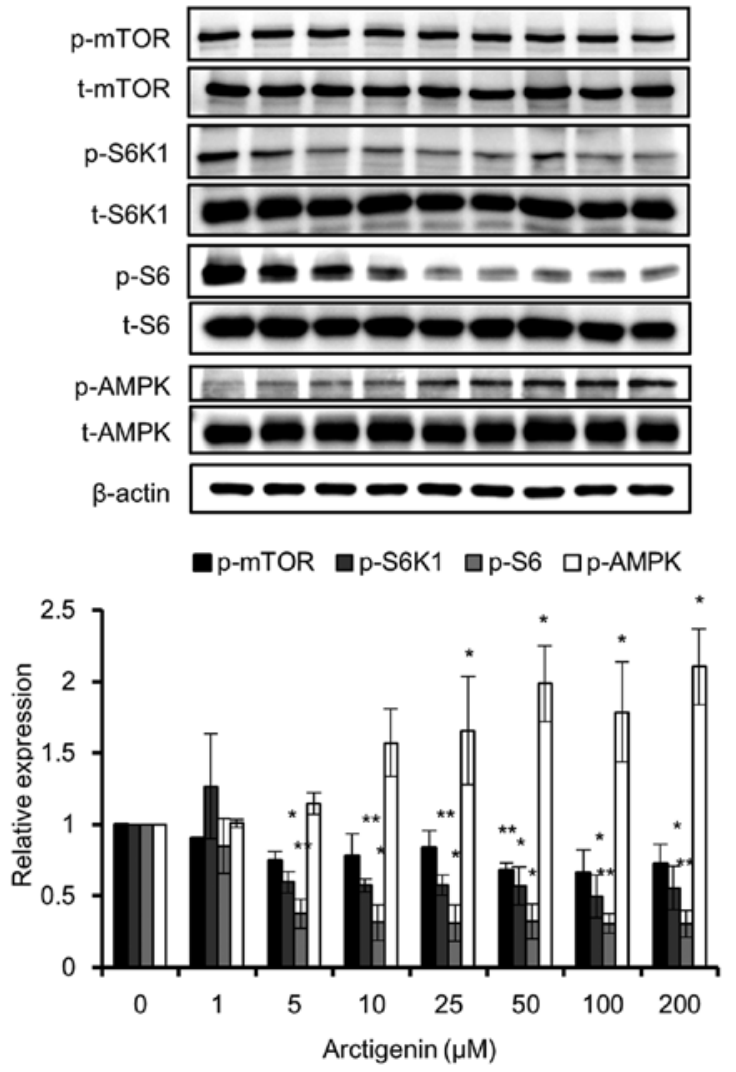

B

Arctigenin $(\mu \mathrm{M}) 0 \quad 1 \quad 2.5 \quad 5 \quad 10 \quad 25 \quad 50 \quad 100200$
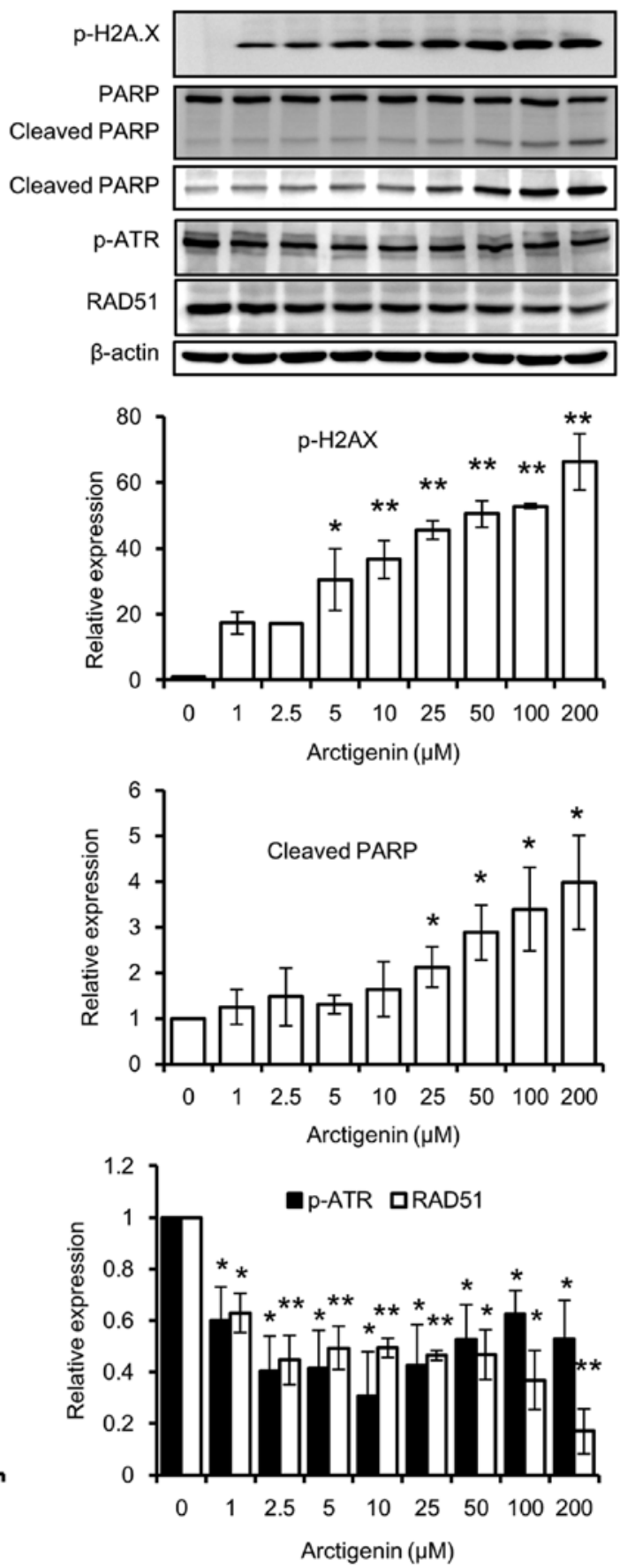

Figure 3. In MCF-7 cells arctigenin treatment resulted in autophagy-induced cell death and DNA damage, by inhibiting mTOR downstream effector molecules (A) LC3-I and LC3-II levels were measured by western blot analysis, and the LC3-II/LC3-I ratio denotes the conversion of LC3-I to LC3-II that marks autophagosome formation and autophagy in MCF-7 cells subjected to treatment with arctigenin for $72 \mathrm{~h}$. (B) Treatment with arctigenin for $72 \mathrm{~h}$ led to extensive DNA damage, as shown by p-H2A.X and PARP cleavage. The levels of DNA repair response proteins, p-ATR and RAD51, were found to be decreased. (C) Western blots and quantification of the phosphorylated/active forms of proteins of the mTOR pathway and AMPK. Graphs represent the means \pm SD of at least 3 independent experiments. $\mathrm{P}$-values were compared to the controls treated with $0 \mu \mathrm{M}$ arctigenin; ${ }^{*} \mathrm{P}<0.05$ and ${ }^{* *} \mathrm{P}<0.01$.

The levels of the DNA repair response proteins, RAD51 (34) and phosphorylated ATR (35), which are increased in cases of DNA damage, were found to be decreased. This suggested that the DNA repair response was inadequate (Fig. 3B). Although phosphorylated H2A.X and cleaved PARP are both considered to be markers of apoptosis, specifically they are markers of DNA damage and cell death (33). In this study, apoptosis was ruled out as the levels of apoptosis signaling proteins were not affected, and therefore, we hypothesized that DNA damage may have occurred due to autophagic cell death.

Autophagy is a highly conserved process that is tightly regulated by several pathways. One of the well-studied regulators of autophagy is the mTOR pathway, which directly inhibits autophagy (28). The induction of autophagy by arctigenin 
A

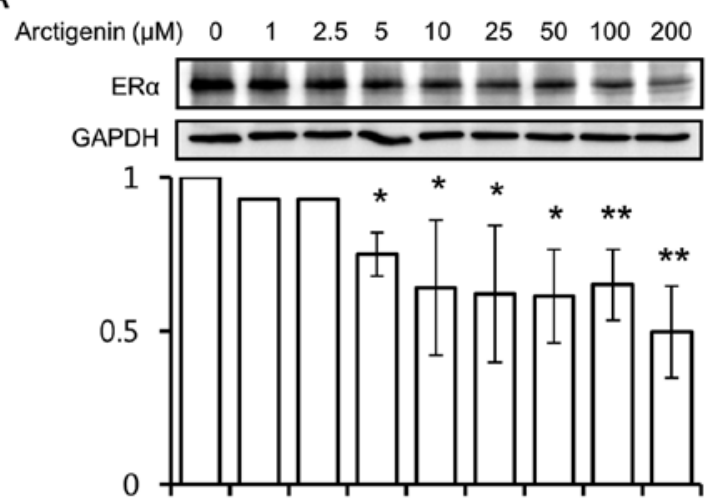

C
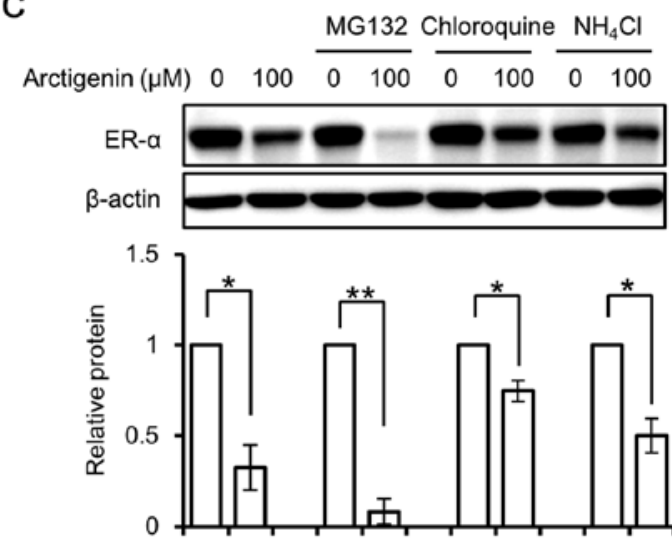

E

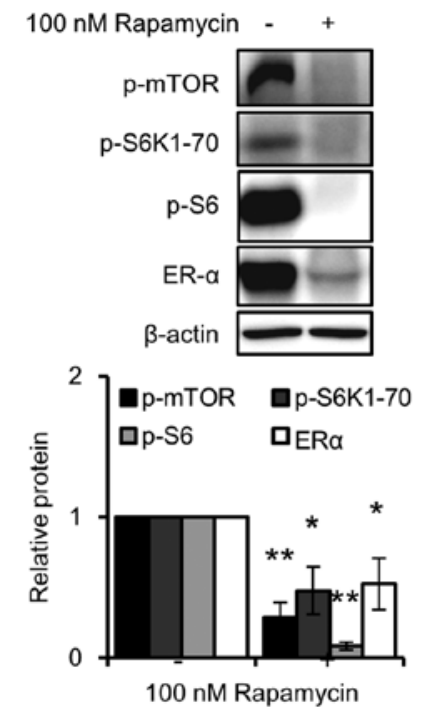

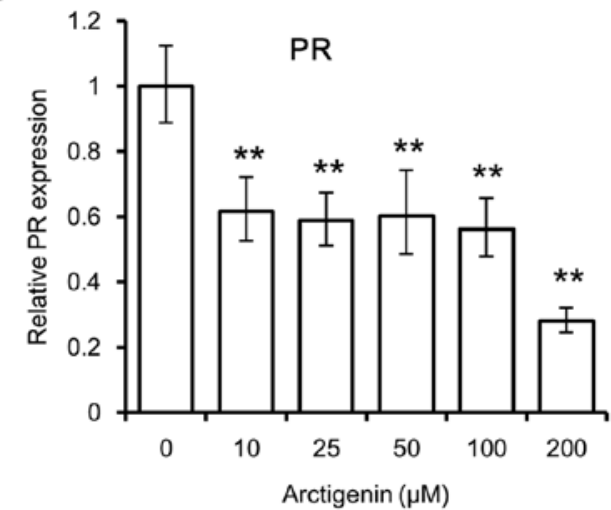

D
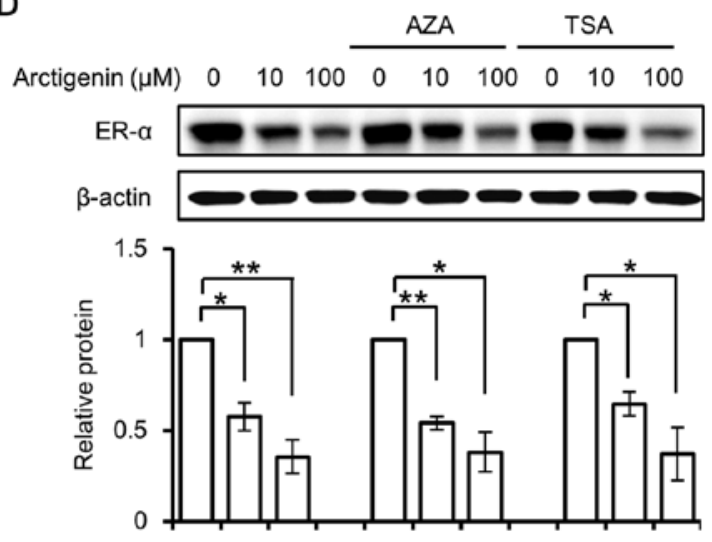

G
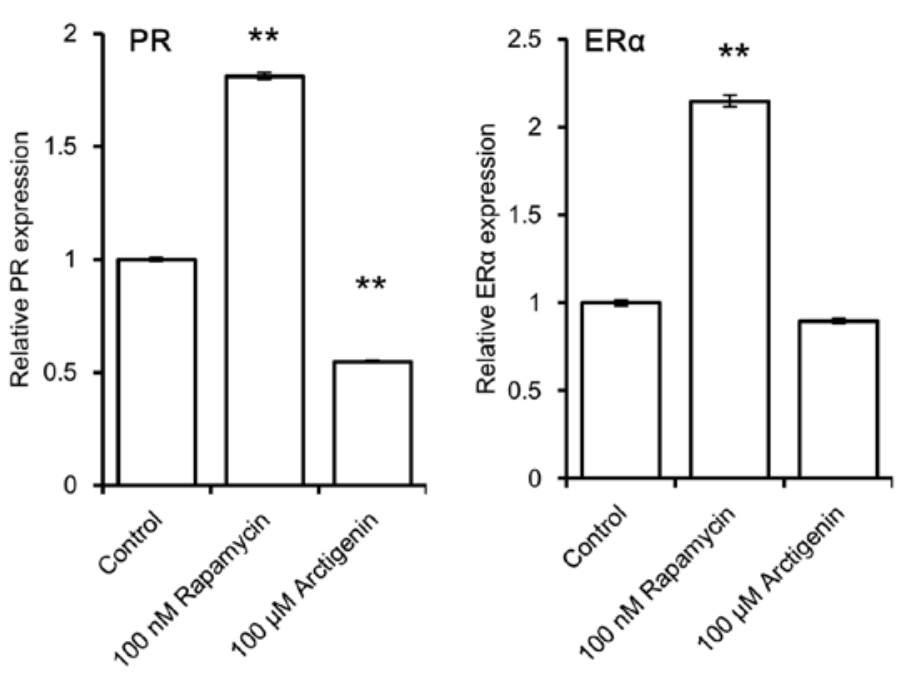

Figure 4. Inhibition of the mTOR pathway molecules by arctigenin decreased ER $\alpha$ protein expression and its downstream signaling in MCF-7 human breast cancer cells. (A) ER $\alpha$ protein expression was found to be decreased by western blot analysis of arctigenin-treated MCF-7 cells. (B) Real-time PCR data revealed that the mRNA levels of ERE responsive PR gene were also suppressed. (C) Inhibition of protein degradation using proteasomal degradation inhibitor (MG132) and inhibitors of lysosomal degradation (chloroquine and $\mathrm{NH}_{4} \mathrm{Cl}$ ) failed to reverse the arctigenin-induced decrease in ER $\alpha$, as shown by western blot analysis. (D) Western blot analysis also confirmed that pre-treatment with DNA methylation inhibitor (AZA) and histone deacetylation inhibitor (TSA) failed to restore the decreased ER $\alpha$ levels induced by arctigenin treatment. (E) Inhibition of mTOR pathway using rapamycin resulted in decreased ER $\alpha$ protein expression, as measured by western blot analysis in MCF-7 cells. (F) Real-time PCR also demonstrated that in contrast to the inhibitory effects observed with arctigenin, rapamycin treatment led to an increase in the transcription of the ERE responsive gene, PR. (G) Rapamycin treatment increased the mRNA levels of ER $\alpha$, measured by real-time PCR, but arctigenin treatment had no affect. Graphs represent the means \pm SD of at least 3 independent experiments. P-values were compared to the corresponding controls; ${ }^{*} \mathrm{P}<0.05$ and ${ }^{* *} \mathrm{P}<0.01$.

via the inhibition of the mTOR pathway has previously been reported in other cell lines $(11,20,29-31)$. In line with the findings of these previous studies, we found that arctigenin treatment inhibited downstream effector molecules of mTOR by suppressing the activation of ribosomal protein S6 and its kinase (Fig. 3C). A crosstalk between mTOR and AMPK 
pathways has been well defined (28). The phosphorylation of AMPK is a marker of low energy in cells and has also been found to be activated prior to autophagy (36). Predictably, even in our study, we detected the increased phosphorylation of AMPK with arctigenin treatment (Fig. 3C). Taken together, our data suggested that arctigenin inhibited downstream effector molecules of the mTOR signaling pathway in the MCF-7 cells, resulting in autophagic cell death and DNA damage.

Inhibition of mTOR pathway by arctigenin results in a decreased expression of ER $\alpha$ and its downstream signaling. Although we found that arctigenin exerted cytotoxic effects on ER $\alpha$-positive MCF-7 cells, as it is a phytoestrogen, we wished to determine whether it interferes with the cytotoxic effects of tamoxifen. Tamoxifen therapy is most widely used in the treatment of hormone-responsive cancers. It acts by binding to ER $\alpha$ and blocking its downstream signaling (37). Upon arctigenin treatment, we observed a dose-dependent decrease in ER $\alpha$ protein expression (Fig. 4A) in the MCF-7 cells. Predictably, a corresponding decrease in the downstream transcription of the ERE responsive gene, PR (Fig. 4B) was also observed. Subsequently, we wished to elucidate the mechanisms behind this effect.

First, we examined whether the arctigenin-induced decrease in ER $\alpha$ expression was due to an increase in protein degradation. In the absence of a substrate, the half-life of $\mathrm{ER} \alpha$ is up to 5 days. However, binding to estradiol accelerates the ER $\alpha$ turnover and reduces its half-life to approximately $3 \mathrm{~h}$ (38). Although the exact mechanisms are unclear to date, it is known that substrate-induced proteolysis, via the ubiquitin proteasome pathway, is required for the activation of ER $\alpha$ receptors (38). In this study, the cells were treated with inhibitors of proteasomal degradation (38) (MG132) and lysosomal degradation (chloroquine and $\mathrm{NH}_{4} \mathrm{Cl}$ ) prior to arctigenin treatment. This did not hinder the decrease in ER $\alpha$ expression induced by arctigenin (Fig. 4C). This suggested that arctigenin treatment did not influence protein degradation in the MCF-7 cells.

Second, we investigated whether epigenetic modifications play a role in the arctigenin-induced decrease in ER $\alpha$ expression (39). It has been reported that arctigenin induces histone modification in ER-negative breast cancer cells (8). Therefore, we wished to determine whether arctigenin decreased ER $\alpha$ expression by altering the enzymes involved in DNA methylation or histone modifications. Pre-treatment with inhibitors of DNA methylation (AZA) or histone deacetylation (TSA) failed to have any effect on the arctigenin-induced inhibition of ER $\alpha$ protein expression (Fig. 4D).

Finally, we examined whether mTOR inhibition would result in a decreased ER $\alpha$ expression. Similar to treatment with arctigenin, treatment with rapamycin, which is a specific mTOR inhibitor, also inhibited ER $\alpha$ protein expression (Fig. 4E), suggesting that mTOR inhibition could lead to a decreased ER $\alpha$ protein expression, probably due to protein synthesis inhibition. However, in contrast to the effects of arctigenin, the results of real-time PCR revealed that the mRNA levels of the downstream ERE responsive gene, PR (Fig. 4F), and those of ER $\alpha$ (Fig. 4G) were found to be increased with rapamycin treatment. It has been previously reported that growth factors may inhibit PR expression via a non-genomic
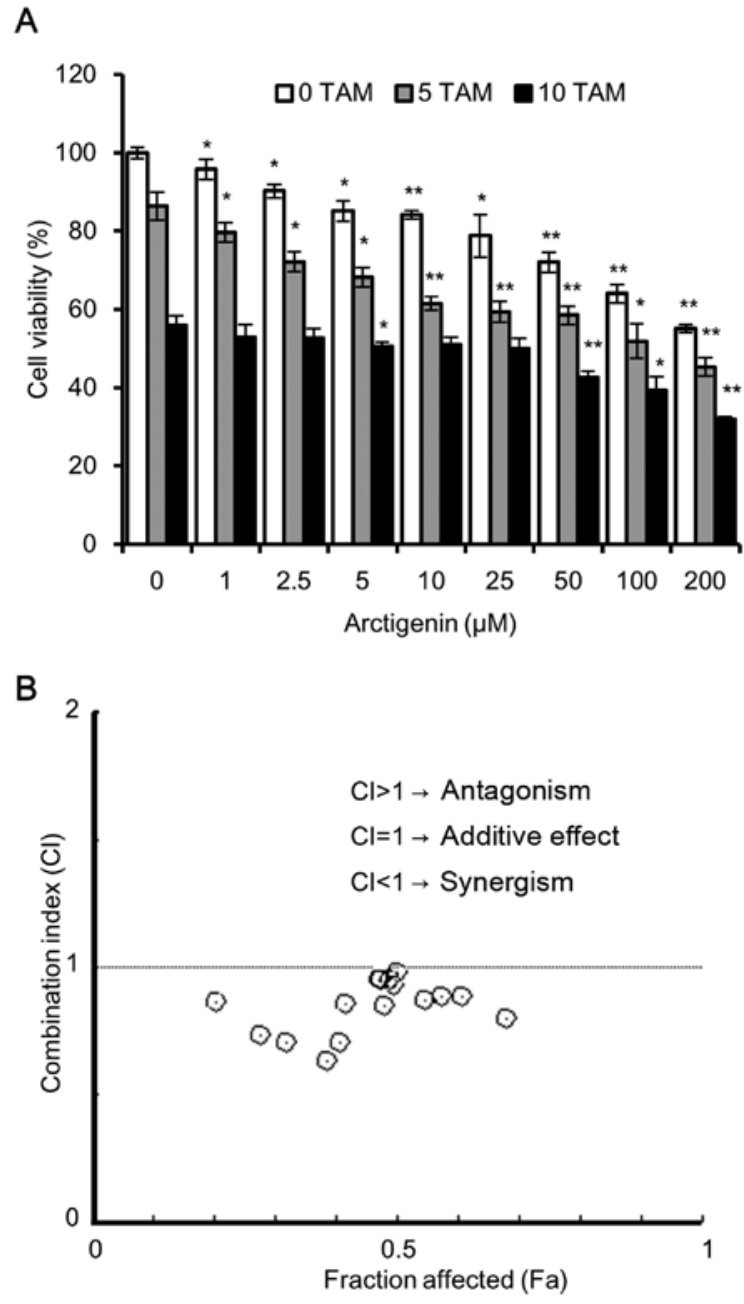

Figure 5. Arctigenin enhanced the cytotoxic effect of tamoxifen on MCF-7 human breast cancer cells. (A) SRB cell proliferation assay of cells treated with various concentrations of arctigenin in combination with 0,5 , or $10 \mu \mathrm{M}$ tamoxifen (TAM) for $72 \mathrm{~h}$. (B) The isobologram and combination-index analyses of drug interaction based on the concentration-effect data calculated by the Compusyn software demonstrated that arctigenin combined with tamoxifen had a synergistic cytotoxic effect on MCF-7 cells. Graphs represent the means \pm SD of at least 3 independent experiments. P-values were compared to the corresponding controls treated with $0 \mu \mathrm{M}$ arctigenin; ${ }^{*} \mathrm{P}<0.05$ and ${ }^{* *} \mathrm{P}<0.01$

$\mathrm{PI} 3 \mathrm{~K} / \mathrm{Akt} / \mathrm{mTOR}$-dependent pathway that is independent of ER (40); the exact mechanisms responsible for this remain to be elucidated. We hypothesized that removing this inhibition with an mTOR inhibitor could lead to an increased transcription of PR. However, we did not further pursue the mechanisms of action of rapamycin, since it was beyond the scope of this study. Arctigenin decreased the mRNA levels of PR, but had no effect on those of ER $\alpha$ compared to the control. This suggests that the mTOR and ER pathways are tightly regulated at multiple levels. On the whole, our data indicated that arctigenin inhibited mTOR downstream effector molecules, including protein synthesis, and hence the synthesis of ER $\alpha$.

\section{Co-treatment of the MCF-7 cells with arctigenin and tamoxifen} exerts a synergistic effect. Since we observed that arctigenin treatment led to a decrease in ER $\alpha$ expression, it is possible that it could affect the sensitivity of MCF-7 cells to tamoxifen. To assess cell cytotoxicity, we treated the MCF-7 cells with 


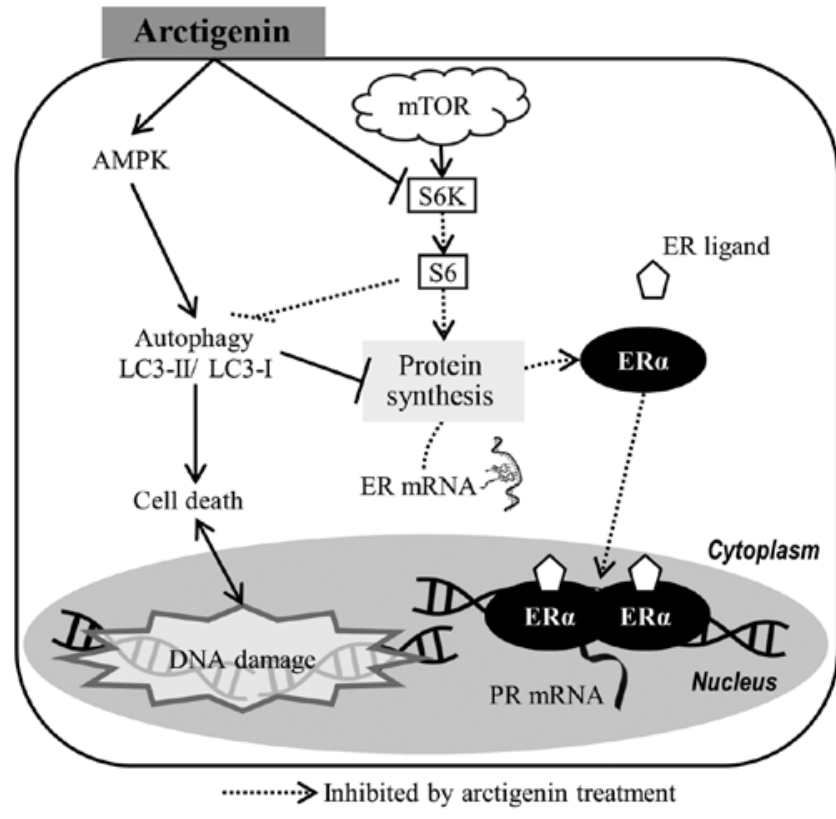

Figure 6. Proposed mechanisms of cytotoxicity exerted by arctigenin on ER-positive MCF-7 human breast cancer cells. Arctigenin inhibited mTOR downstream effector molecules, resulting in autophagic cell death and DNA damage. The inhibition of mTOR signaling molecules, along with autophagy, also suppressed protein synthesis, resulting in decreased $\mathrm{ER} \alpha$ protein expression and its signaling downstream

various concentrations of arctigenin in the presence of 5 or $10 \mu \mathrm{M}$ tamoxifen. The results of SRB assay revealed that both arctigenin and tamoxifen inhibited MCF-7 cell viability, in a concentration-dependent manner, with an enhanced effect from combined treatment (Fig. 5A). To quantitatively validate our observations, we used the method described in the study by Chou and Talalay (24) and calculated the dose-effect associations for each drug and their combinations using Compusyn software. The combination index (CI) and the corresponding effect level, designated as the fraction affected ( $\mathrm{Fa})$, were calculated for each concentration, and the Fa-CI graph was plotted. The CI values provide a quantitative definition for the additive effect $(\mathrm{CI}=1)$, synergistic effect $(\mathrm{CI}<1)$, and antagonistic effect $(\mathrm{CI}>1)$ in drug combinations. As shown in Fig. 5B, for most combinations of tamoxifen and arctigenin, the $\mathrm{CI}$ was $<1$, indicating that arctigenin treatment did not interfere with the sensitivity of the cells to tamoxifen, but indeed had a synergistic effect. Hence, we also propose that arctigenin may safely be used as an effective supplement, even for patients undergoing endocrine therapy.

Taken together, our data suggest that the phytoestrogen, arctigenin, inhibited downstream effector molecules of the mTOR pathway in ER-positive MCF-7 human breast cancer cells, leading to autophagy-induced cell death and the downregulation of ER $\alpha$ (Fig. 6). This, however, did not affect the sensitivity of the cells to tamoxifen.

\section{Discussion}

Phytoestrogens are plant-derived chemical compounds with estrogenic activities (41). Their affinities for estrogen receptors are at least 1,000-10,000-fold lower than those of estradiol; nonetheless, they are capable of binding to estrogen receptors and initiating or disrupting estrogen-dependent transcriptions, which could then lead to cell proliferation or growth inhibition. The role of phytoestrogens on breast cancer cells is a highly debated topic. Although phytoestrogens have been found to have an agonistic affect that can lead to cell proliferation in vitro (42), it has been found that their consumption has the opposite effect, presenting with benefits of cancer prevention (41). These anomalies remain unresolved; however, the benefits of phytoestrogens on breast cancer cells are likely mediated through other pathways, and not through estrogen signaling. Since arctigenin and its metabolites have been reported to have estrogenic properties (23), an investigation of the effects of arctigenin on ER $\alpha$-positive breast cancer cells is warranted.

In this study, we demonstrated that arctigenin was cytotoxic to MCF-7 human breast cancer cells. Previously, several studies have reported the antitumor effects of arctigenin by the induction of apoptosis (8-12,14-16,18). However, in this study, arctigenin did not trigger any apoptotic signals. Phosphorylated H2A.X and cleaved PARP were found to be induced by arctigenin. PARP cleavage in the arctigenin-treated MCF-7 cells has been recently reported (43). However, since the levels of the effector caspase, caspase-7 and upstream signals were not altered, it was deduced that cell death may have involved nonapoptotic pathways, and p-H2A.X and PARP cleavage were due to extensive DNA damage. The possibility of arctigenin causing necroptosis was also ruled out due to the absence of the necroptosis marker, RIPK3.

In this study, arctigenin was found to inhibit mTOR downstream effector molecules. The inhibition of the mTOR pathway is known to directly induce autophagy as mTOR inhibits autophagy via Ulk1 (28), and suppresses protein translation, cell growth and proliferation, all of which influence tumorigenesis. It has previously been reported that arctigenin inhibits the mTOR pathway, which leads to endoplasmic reticulum stress (29) and apoptosis (11) in liver cancer cells, to an anti-colitis effect in immune cells (30), and to $\beta$-amyloid clearance in an Alzheimer's disease model (31). It has also been reported that arctigenin inhibits mTORC1 activation by binding to ER $\beta$ in Th17 cells (20). Hence, our data also suggest that the mTOR pathway may be an important target site for the effects of arctigenin.

Moreover, arctigenin was also found to significantly downregulate $\mathrm{ER} \alpha$ protein expression and downstream transcription of PR, which is an ERE responsive gene. We ruled out the role of protein degradation and epigenetic modifications in the arctigenin-induced decrease in ER $\alpha$ protein expression using specific inhibitors. The downregulation of ER $\alpha$ protein expression and its transcriptional activity by the mTOR inhibitor, everolimus, has previously been reported (44). We also compared the effects of arctigenin on MCF-7 cells to another well-known mTOR inhibitor, rapamycin, and found a decreased $\mathrm{ER} \alpha$ protein expression. Hence, we inferred that the decrease in ER $\alpha$ expression with arctigenin treatment may have been a consequence of the inhibition of the mTOR pathway molecules, particularly due to the decreased activation of ribosomal protein S6, which is required for protein synthesis. However, in contrast to arctigenin, rapamycin increased the mRNA levels of $\mathrm{ER} \alpha$ and those of the downstream transcription of ERE gene. 
Although the exact mechanisms involved are unclear, PI3K/ Akt/mTOR has been reported to inhibit ERE transcription. There have been reports suggesting that during IGF-I signaling, the removal of this inhibition with an mTOR inhibitor could lead to increased transcription of PR (40). This indicates that the ER and mTOR pathways are inter-related and are regulated at several levels, and the effects of each drug need to be evaluated individually to better ascertain their pharmacological effects. Our data suggest that for patients with breast cancer, arctigenin may be a better inhibitor of mTOR compared with rapamycin, as it does not increase ERE transcription, which could lead to cell proliferation.

The decrease in ER $\alpha$ protein expression compelled us to determine whether arctigenin interferes with the effect of tamoxifen, and found that arctigenin in combination with tamoxifen treatment resulted in a synergistic effect. Hence, according to our data, the effects of arctigenin on breast cancer are likely a double-edged sword. Arctigenin inhibited both ER and mTOR downstream effector molecules. The benefits of inhibiting ER signaling in cancer therapy have been shown by the use of tamoxifen. More recently, fulvestrant, a 'real' anti-estrogen, is gaining popularity as a means to treat breast cancer therapy for its effectiveness in binding, blocking, and degrading the ER (45). We demonstrated that arctigenin also decreased ER protein expression and blocked down-stream signaling. Moreover, we showed that arctigenin inhibited mTOR downstream effector molecules. Preclinical studies have shown that ER-positive breast cancer cells require hyperactivation of the PI3K/Akt/mTOR pathway for an adaptation to hormone-independent growth after long-term estrogen deprivation. There is evidence to indicate that the combined inhibition of ER and the mTOR pathway may be beneficial in the early lines of treatment (46). Drug combination studies have shown that mTOR inhibitors exert synergistic effects with anti-estrogens, including tamoxifen $(47,48)$, and blocking both pathways not only enhances the antitumor activity, but also reverses the resistance to endocrine therapy. Finally, since arctigenin is a plant extract, it may be safe for human consumption, as it has no notable side-effects. Burdock root, which is rich in arctigenin, has been consumed as a vegetable and in the form of tea, with no reported side-effects. This may explain the success of Essiac tea, which is an herbal remedy for breast cancer; its main ingredient is Burdock root (7). The antitumor effects of arctigenin on mice with breast cancer tumor xenografts have also been reported (18). Hence, it is worth noting that arctigenin may have potential benefits, including its efficacy as a natural alternative to conventional hormone-responsive therapy.

In conclusion, the phytoestrogen, arctigenin, inhibited mTOR downstream effector molecules in ER-positive MCF-7 human breast cancer cells, leading to autophagy-induced cell death and down regulation of ER $\alpha$. Therefore, we suggest that arctigenin may not only be safe for consumption by patients with hormone-sensitive cancers, but its synergistic effects with tamoxifen may also make this a viable and effective co-treatment.

\section{Acknowledgements}

Not applicable.

\section{Funding}

This study was supported by the Basic Science Research Program through the National Research Foundation of Korea (NRF) funded by the Ministry of Education (2015R1D1A1A01058841).

\section{Availability of data and materials}

The analyzed data sets generated during the study are available from the corresponding author on reasonable request.

\section{Authors' contributions}

TM, KSL, SK and KSN designed the experiments; TM performed the experiments; TM, KSL, SK and KSN analyzed and discussed the data; TM wrote the article. All authors have reviewed and approved the manuscript.

\section{Ethics approval and consent to participate}

Not applicable.

\section{Consent for publication}

Not applicable.

\section{Competing interests}

The authors declare that they have no competing interests.

\section{References}

1. Chan YS, Cheng LN, Wu JH, Chan E, Kwan YW, Lee SM, Leung GP, Yu PH and Chan SW: A review of the pharmacological effects of Arctium lappa (burdock). Inflammopharmacology 19: 245-254, 2011.

2. Hayashi K, Narutaki K, Nagaoka Y, Hayashi T and Uesato S: Therapeutic effect of arctiin and arctigenin in immunocompetent and immunocompromised mice infected with influenza A virus. Biol Pharm Bull 33: 1199-1205, 2010.

3. Swarup V, Ghosh J, Mishra MK and Basu A: Novel strategy for treatment of Japanese encephalitis using arctigenin, a plant lignan. J Antimicrob Chemother 61: 679-688, 2008.

4. Kim Y, Hollenbaugh JA, Kim DH and Kim B: Novel PI3K/Akt inhibitors screened by the cytoprotective function of human immunodeficiency virus type 1 Tat. PLoS One 6: e21781, 2011.

5. Kang HS, Lee JY and Kim CJ: Anti-inflammatory activity of arctigenin from Forsythiae Fructus. J Ethnopharmacol 116: 305-312, 2008.

6. Lee JY and Kim CJ: Arctigenin, a phenylpropanoid dibenzylbutyrolactone lignan, inhibits type I-IV allergic inflammation and pro-inflammatory enzymes. Arch Pharm Res 33: 947-957, 2010.

7. Zick SM, Sen A, Feng Y, Green J, Olatunde S and Boon H: Trial of Essiac to ascertain its effect in women with breast cancer (TEA-BC). J Altern Complement Med 12: 971-980, 2006.

8. Hsieh CJ, Kuo PL, Hsu YC, Huang YF, Tsai EM and Hsu YL: Arctigenin, a dietary phytoestrogen, induces apoptosis of estrogen receptor-negative breast cancer cells through the ROS/ p38 MAPK pathway and epigenetic regulation. Free Radic Biol Med 67: 159-170, 2014.

9. Huang K, Li LA, Meng YG, You YQ, Fu XY and Song L: Arctigenin promotes apoptosis in ovarian cancer cells via the iNOS/NO/STAT3/survivin signalling. Basic Clin Pharmacol Toxicol 115: 507-511, 2014.

10. Jeong JB, Hong SC, Jeong HJ and Koo JS: Arctigenin induces cell cycle arrest by blocking the phosphorylation of $\mathrm{Rb}$ via the modulation of cell cycle regulatory proteins in human gastric cancer cells. Int Immunopharmacol 11: 1573-1577, 2011. 
11. Jiang X, Zeng L, Huang J, Zhou H and Liu Y: Arctigenin, a natural lignan compound, induces apoptotic death of hepatocellular carcinoma cells via suppression of PI3-K/Akt signaling. J Biochem Mol Toxicol 29: 458-464, 2015.

12. Kim JY, Hwang JH, Cha MR, Yoon MY, Son ES, Tomida A, Ko B, Song SW, Shin-ya K, Hwang YI, et al: Arctigenin blocks the unfolded protein response and shows therapeutic antitumor activity. J Cell Physiol 224: 33-40, 2010.

13. Susanti S, Iwasaki H, Inafuku M, Taira N and Oku H: Mechanism of arctigenin-mediated specific cytotoxicity against human lung adenocarcinoma cell lines. Phytomedicine 21: 39-46, 2013.

14. Wang HQ, Jin JJ and Wang J: Arctigenin enhances chemosensitivity to cisplatin in human nonsmall lung cancer H460 cells through downregulation of survivin expression. J Biochem Mol Toxicol 28: 39-45, 2014.

15. Wang L, Zhao F and Liu K: Induction of apoptosis of the human leukemia cells by arctigenin and its mechanism of action. Yao Xue Xue Bao 43: 542-547, 2008 (In Chinese).

16. Yang S, Ma J, Xiao J, Lv X, Li X, Yang H, Liu Y, Feng S and Zhang Y: Arctigenin anti-tumor activity in bladder cancer T24 cell line through induction of cell-cycle arrest and apoptosis. Anat Rec (Hoboken) 295: 1260-1266, 2012.

17. Kang K, Lee HJ, Yoo JH, Jho EH, Kim CY, Kim M and Nho CW: Cell and nuclear enlargement of SW480 cells induced by a plant lignan, arctigenin: Evaluation of cellular DNA content using fluorescence microscopy and flow cytometry. DNA Cell Biol 30: 623-629, 2011.

18. Feng T, Cao W, Shen W, Zhang L, Gu X, Guo Y, Tsai HI, Liu X, Li J, Zhang J, et al: Arctigenin inhibits STAT3 and exhibits anticancer potential in human triple-negative breast cancer therapy. Oncotarget 8: 329-344, 2017.

19. Maxwell T, Chun SY, Lee KS, Kim S and Nam KS: The anti-metastatic effects of the phytoestrogen arctigenin on human breast cancer cell lines regardless of the status of ER expression. Int J Oncol 50: 727-735, 2017.

20. Wu X, Tong B, Yang Y, Luo J, Yuan X, Wei Z, Yue M, Xia Y and Dai Y: Arctigenin functions as a selective agonist of estrogen receptor $\beta$ to restrict mTORC1 activation and consequent Th17 differentiation. Oncotarget 7: 83893-83906, 2016.

21. Bardin A, Boulle N, Lazennec G, Vignon F and Pujol P: Loss of ERbeta expression as a common step in estrogen-dependent tumor progression. Endocr Relat Cancer 11: 537-551, 2004.

22. Skliris GP, Munot K, Bell SM, Carder PJ, Lane S, Horgan K, Lansdown MR, Parkes AT, Hanby AM, Markham AF, et al: Reduced expression of oestrogen receptor beta in invasive breast cancer and its re-expression using DNA methyl transferase inhibitors in a cell line model. J Pathol 201: 213-220, 2003.

23. Xie LH, Ahn EM, Akao T, Abdel-Hafez AA, Nakamura N and Hattori M: Transformation of arctiin to estrogenic and antiestrogenic substances by human intestinal bacteria. Chem Pharm Bull (Tokyo) 51: 378-384, 2003.

24. Chou TC and Talalay P: Quantitative analysis of dose-effect relationships: The combined effects of multiple drugs or enzyme inhibitors. Adv Enzyme Regul 22: 27-55, 1984

25. Liang Y, Yan C and Schor NF: Apoptosis in the absence of caspase 3. Oncogene 20: 6570-6578, 2001.

26. Vandenabeele P, Galluzzi L, Vanden Berghe T and Kroemer G: Molecular mechanisms of necroptosis: An ordered cellular explosion. Nat Rev Mol Cell Biol 11: 700-714, 2010.

27. Wu X, Wu MY, Jiang M, Zhi Q, Bian X, Xu MD, Gong FR, Hou J, Tao M, Shou LM, et al: TNF- $\alpha$ sensitizes chemotherapy and radiotherapy against breast cancer cells. Cancer Cell Int 17: 13, 2017.

28. Jung CH, Ro SH, Cao J, Otto NM and Kim DH: mTOR regulation of autophagy. FEBS Lett 584: 1287-1295, 2010.

29. Gu Y, Sun XX, Ye JM, He L, Yan SS, Zhang HH, Hu LH, Yuan JY and Yu Q: Arctigenin alleviates ER stress via activating AMPK. Acta Pharmacol Sin 33: 941-952, 2012

30. Wu X, Dou Y, Yang Y, Bian D, Luo J, Tong B, Xia Y and Dai Y: Arctigenin exerts anti-colitis efficacy through inhibiting the differentiation of Th1 and Th17 cells via an mTORC1-dependent pathway. Biochem Pharmacol 96: 323-336, 2015.
31. Zhu Z, Yan J, Jiang W, Yao XG, Chen J, Chen L, Li C, Hu L, Jiang $\mathrm{H}$ and Shen $\mathrm{X}$ : Arctigenin effectively ameliorates memory impairment in Alzheimer's disease model mice targeting both $\beta$-amyloid production and clearance. J Neurosci 33: 13138-13149, 2013.

32. Yoshioka A, Miyata H, Doki Y, Yamasaki M, Sohma I, Gotoh K, Takiguchi S, Fujiwara Y, Uchiyama Y and Monden M: LC3, an autophagosome marker, is highly expressed in gastrointestinal cancers. Int J Oncol 33: 461-468, 2008.

33. Chanoux RA, Yin B, Urtishak KA, Asare A, Bassing $\mathrm{CH}$ and Brown EJ: ATR and H2AX cooperate in maintaining genome stability under replication stress. J Biol Chem 284: 5994-6003, 2009.

34. Koehn H, Magan N, Isaacs RJ and Stowell KM: Differential regulation of DNA repair protein Rad51 in human tumour cell lines exposed to doxorubicin. Anticancer Drugs 18: 419-425, 2007.

35. Maier P, Hartmann L, Wenz F and Herskind C: Cellular pathways in response to ionizing radiation and their targetability for tumor radiosensitization. Int J Mol Sci 17: 1-32, 2016.

36. Meijer AJ and Codogno P: Autophagy: Regulation by energy sensing. Curr Biol 21: R227-R229, 2011.

37. Shagufta and Ahmad I: Tamoxifen a pioneering drug: An update on the therapeutic potential of tamoxifen derivatives. Eur J Med Chem 143: 515-531, 2018

38. Lonard DM, Nawaz Z, Smith CL and O'Malley BW: The $26 \mathrm{~S}$ proteasome is required for estrogen receptor-alpha and coactivator turnover and for efficient estrogen receptor-alpha transactivation. Mol Cell 5: 939-948, 2000.

39. Pinzone JJ, Stevenson H, Strobl JS and Berg PE: Molecular and cellular determinants of estrogen receptor alpha expression. Mol Cell Biol 24: 4605-4612, 2004

40. Cui X, Zhang P, Deng W, Oesterreich S, Lu Y, Mills GB and Lee AV: Insulin-like growth factor-I inhibits progesterone receptor expression in breast cancer cells via the phosphatidylinositol 3-kinase/Akt/mammalian target of rapamycin pathway: Progesterone receptor as a potential indicator of growth factor activity in breast cancer. Mol Endocrinol 17: 575-588, 2003.

41. Rice S and Whitehead SA: Phytoestrogens and breast cancer-promoters or protectors? Endocr Relat Cancer 13: 995-1015, 2006.

42. Matsumura A, Ghosh A, Pope GS and Darbre PD: Comparative study of oestrogenic properties of eight phytoestrogens in MCF7 human breast cancer cells. J Steroid Biochem Mol Biol 94 431-443, 2005.

43. Lee J, Imm JY and Lee SH: $\beta$-catenin mediates anti-adipogenic and anticancer effects of arctigenin in preadipocytes and breast cancer cells. J Agric Food Chem 65: 2513-2520, 2017

44. Lui A, New J, Ogony J, Thomas S and Lewis-Wambi J: Everolimus downregulates estrogen receptor and induces autophagy in aromatase inhibitor-resistant breast cancer cells. BMC Cancer 16: 487, 2016.

45. Nathan MR and Schmid P: A review of fulvestrant in breast cancer. Oncol Ther 5: 17-29, 2017.

46. Miller TW, Hennessy BT, González-Angulo AM, Fox EM, Mills GB, Chen H, Higham C, García-Echeverría C, Shyr Y and Arteaga CL: Hyperactivation of phosphatidylinositol-3 kinase promotes escape from hormone dependence in estrogen receptorpositive human breast cancer. J Clin Invest 120: 2406-2413, 2010.

47. Chumsri S, Sabnis G, Tkaczuk K and Brodie A: mTOR inhibitors: Changing landscape of endocrine-resistant breast cancer. Future Oncol 10: 443-456, 2014.

48. Ghayad SE, Bieche I, Vendrell JA, Keime C, Lidereau R, Dumontet $\mathrm{C}$ and Cohen PA: mTOR inhibition reverses acquired endocrine therapy resistance of breast cancer cells at the cell proliferation and gene-expression levels. Cancer Sci 99: 1992-2003, 2008. 